\title{
Roche Cárcel, Juan Antonio (Ed.) (2020): Las sociedades difusas. La construcción/deconstrucción sociocultural de fronteras y márgenes. Barcelona: Anthropos, 334 pp. ISBN: 978-84-17556-47-1.
}

El profesor de la Universidad de Alicante, Juan A. Roche Cárcel edita un volumen bajo el sugerente título de Las sociedades difusas con el objetivo de explorar cómo los límites y las fronteras tradicionales parecen diluirse y reconfigurarse en las sociedades actuales en muy diversos ámbitos de la vida social y cultural. Este es un objetivo de especial pertinencia pues, en palabras del mismo autor: "En las sociedades contemporáneas, los límites, los márgenes y las fronteras han perdido definición y han sufrido un proceso de indeterminación, de confusión o de hibridación, aunque, eso sí, de una manera compleja, contradictoria y no vacía de paradojas, pues, simultáneamente, se han visto reforzados o disueltos" (p. 5). Los límites en las sociedades actuales parecen encontrarse, por lo tanto, dentro de un entorno vaporoso, en el que "todo lo sólido se desvanece en el aire". O, por utilizar la metáfora de Z. Bauman, en un entorno "líquido" donde las fronteras y los límites "sólidos" parecen retroceder e incluso desparecer.

El texto se publica dentro de la colección Autores, Textos y Temas de Ciencias Sociales dirigida por Josetxo Beriain para la editorial Anthropos. En él se encuentra el trabajo de 24 autores de muy diversa procedencia: Fernando Aguiar, Maya Aguiluz-Ibargüen, Juan M. Agulles Martos, Angel Belzunegui-Eraso, José A. Bergua, Josetxo Beriain, Marta Calvo Merino, Ángel Enrique Carretero Pasín, Juan R. Coca, Andrés Dávila Legerén, Miguel A. V. Ferreira, Carina Giletta, Javier Gómez, Vicente Huici Urmeneta, Antonio Martín-Cabello, Ignacio Mendiola, J. Javier Moreno Sánchez, Inma Pastor Gosálbez, Juan A. Roche Cárcel, Juan Antonio Rodríguez Sánchez, Celso Sánchez Capdequi, Adrián Scribano, Francisco Sempere Ruiz y Laura Tarabella, que han elaborado un total de 19 textos.

Todos ellos se encuentran agrupados en tres grandes apartados, que intentan dar sentido unitario a una serie de textos con diferentes perspectivas y enfoques, si bien conducidos por un hilo temático común. El primero, bajo la denominación "Teorías sociológicas sobre la indeterminación de fronteras y márgenes" se ocupa del análisis conceptual de las nociones relativas a lo liminar. El primer capítulo del volumen se centra en el menguante papel de las fronteras físicas y en el paralelo auge de las fronteras virtuales o electrónicas. El ciberespacio es un mundo en el que se generan toda una tecnología de los límites, los controles de acceso y la exclusión del otro.

El segundo capítulo se centra en una revisión de los sistemas clasificatorios que se han utilizado, especialmente desde la sociología, para clasificar y dar orden al mundo.

Estos márgenes socialmente establecidos permiten generar marcos de referencia comunes que contribuyen a la gestación de una hegemonía cognitiva. A lo que habría que sumar la desaparición de lo sagrado y transcendente, frente a los secular, lo que altera esos marcos de referencia colectivos. Las nuevas tecnologías generan nuevas experiencias que alteran lo transcendente y los marcos clasificatorios. El siguiente capítulo, "Por una sociología (de lo) imposible", pone el foco en "las distintas clases de fallos, agujeros, fracturas, inconsistencias, resistencias, etc. que impiden que el ser sea, el observar observe y el hacer haga" (p. 59).

El cuarto capítulo, por su parte, sostiene que las fronteras tradicionales se establecían, en lo fundamental, sobre las delimitaciones de lo sagrado y lo profano. En la actualidad, no obstante, parece que esta dicotomía está cediendo y dando lugar a una zona basada en un misticismo secularizado.

El quinto y último capítulo se adentra en las incongruencias de las fronteras físicas en la actualidad, donde los países más democráticos se muestran muchas veces menos respetuosos con los Derechos Humanos de los migrantes que países menos ricos $y$, supuestamente, menos democráticos. La frontera, por lo tanto, es un terreno en el que se debate el concepto y la práctica de la democracia.

El segundo apartado, bajo el rótulo: "Los actores sociales en la construcción/deconstrucción sociocultural de fronteras y márgenes" indaga en el modo en que los actores sociales contribuyen a la redefinición de los límites y las fronteras. En esta parte encontramos textos sobre el tránsito en la frontera turca de los refugiados sirios; la neobiologización del concepto de género; el concepto de límite en la teoría queer; el tránsito fronterizo de colectivos globales como los mochileros o los expatriados corporativos; los migrantes centroamericanos en la llamada Marcha Hondureña hacia los Estados Unidos; las "cirujas" de Argentina y las personas sin hogar. Estos dos últimos textos hablan no ya tanto de las fronteras exteriores, sino de las internas a las sociedades, que muchas veces pasan más desapercibidas y que, sin embargo, pueden ser incluso más duras y excluyentes.

El último apartado, denominado: "Los contextos socioculturales en la construcción/deconstrucción de fronteras y márgenes" recoge una serie de textos que describen la aparición de neocomunidades que tratan precisamente de reconstruir los límites rotos en las sociedades contemporáneas, esto es, de generar cohesión social en un mundo tendente a la individualización. Encontramos también textos sobre fronteras, límites y movilidad urbanas, sobre la noción de raza y de racialización en América Latina, donde están surgiendo organizaciones conservadoras que estructuran su discurso en torno a estos conceptos. Los 
dos últimos artículos tratan como el concepto de límite y frontera afectan a la esfera de la salud: sobre la "capacidad" y la "discapacidad" y sobre las llamadas "enfermedades raras" y las "enfermedades comunes".

La monografía reseñada es una aportación que se centra en uno de los temas capitales de nuestro tiempo: los límites y las fronteras, ya que su impacto supera lo político y se difunde hacia ámbitos más sociales y culturales. El manido concepto de identidad no puede entenderse sin el de límite; la identidad supone una frontera, por más que esta sea simbólica, respecto al otro. El libro consigue dar luz a una dinámica compleja y vital, en constante reelaboración, y que impacta significativamente en la vida de las personas y en la estructura de las sociedades. El trabajo de este conjunto de expertos nos permite comprender mejor el mundo en el que estamos viviendo.

Rafael Ravina-Ripoll

(D) https://orcid.org/0000-0001-7007-3123 Universidad de Cadiz, España

rafael.ravina@uca.es

Recibido: 15-09-2021 Aceptado: 01-10-2021 